\title{
The Effect of Electrolyte Temperature on the Electrodeposition of Cuprous Oxide Films
}

\author{
Yuan-Gee Lee ${ }^{1,}$, Jee-Ray Wang ${ }^{1}$, Miao-Ju Chuang ${ }^{1}{ }^{*}$, Der-Wei Chen ${ }^{2}$, Kung-Hsu Hou ${ }^{2, *}$ \\ ${ }^{1}$ Department of Automation Engineering and Institute of Mechatronoptic Systems, Changhua, Taiwan \\ ${ }^{2}$ Department of Power Vehicle and Systems Engineering, Chung Cheng Institute of Technology, \\ National Defense University, Taoyuan, Taiwan \\ *E-mail: mjchuang@ctu.edu.tw, khou@ndu.edu.tw, khoucloud@gmail.com
}

doi: $10.20964 / 2017.01 .19$

Received: 10 September 2016 / Accepted: 19 November 2016 / Published: 12 December 2016

\begin{abstract}
Cuprous oxide $\left(\mathrm{Cu}_{2} \mathrm{O}\right)$ thin films were deposited on indium tin oxide (ITO) coated glass by electrochemical deposition at different electrolyte temperature. The electrodeposition process was found to be a reductive irreversible process with a major phase, $\mathrm{Cu}_{2} \mathrm{O}$, and appreciable amount of $\mathrm{CuO}$. With the increasing temperature, the microstructure varied from fine grains, amorphous-like, to coarse pyramids, well-crystallized, which were identified as the texture development transforming from (200) to (111). Not only was the increasing temperature of electrodepostion found to induce the optical redshift of band gap from 2.19 to $2.68 \mathrm{eV}$ but it inhabited electrical transmittance with resistivity from 11.28 to $0.24 \Omega-\mathrm{cm}$.
\end{abstract}

Keywords: electrodeposition, irreversible, phase transformation, band gap, and resistivity

\section{FULL TEXT}

(C) 2017 The Authors. Published by ESG (www.electrochemsci.org). This article is an open access article distributed under the terms and conditions of the Creative Commons Attribution license (http://creativecommons.org/licenses/by/4.0/). 